\title{
Jan Olofsson, a man of great achievements
}

\author{
Manuel Bernal-Sprekelsen ${ }^{1} \cdot$ Roland Laszig $^{2} \cdot$ Marc Remacle $^{3}$
}

Published online: 24 June 2016

(c) Springer-Verlag Berlin Heidelberg 2016

After more than 15 years of editorship for our journal, Jan Olofsson has decided to step down. This is the time to thank him for all he has accomplished for the construction of the European ORL-Head and Neck Surgery.

One of the first major contributions of Jan to the literature was the chapters he wrote for the textbook of the Centennial conference on laryngeal cancer, Toronto, 1974. He then established himself not only as a great laryngologist and Head-Neck surgeon, but also as a great scientist.

From Swedish origin, Jan put his department of Bergen, Norway, on the world map of laryngology. The Scandinavian Head and Neck would not be what it is now without his seminal contribution.

A man of great openness and views, he understood that only an International or European platform could allow the Europeans to be truly recognized by our American or Asian colleagues. Without him, IFHNOS, the International Federation of Head and Neck national societies, could not have developed as it is now.

Marc Remacle

marc.remacle01@gmail.com

Manuel Bernal-Sprekelsen

MBERNAL@clinic.cat

Roland Laszig

roland.laszig@uniklinik-freiburg.de

1 Servicio de ORL, Hospital Clínic Universitari, calle Villarroel, 170, Esc. 8, 2A, 08036 Barcelona, Spain

2 Department of Otorhinolaryngology, University Hospital, Freiburg, Albert-Ludwigs-University, Freiburg, Killianstr. 5, 79106 Freiburg, Germany

3 Department of ORL-Head Neck Surgery, CHL-Eich, Rue d'Eich 78, 1460, Luxembourg, Luxembourg
Jan was also the Chair of the Laryngology and Head and Neck Surgery Committee for International Federation of Oto-Rhino-Laryngological Societies (IFOS).

In a period of turmoil, he took over the Presidency of EUFOS, making possible the creation of the Confederation of European ORL-Head and Neck Surgery (CEORL-HNS) by the merging with his sister organization, and he was a founding member of the European Academy.

$\mathrm{He}$ was also among the founding members of the European Laryngological Society (ELS) in January 95 under the Presidency of Oskar Kleinsasser, together with Italo Serafini, Bernard Luboinski, and Mario Andrea.

Jan was himself the President of ELS from 2000 to 2002, completing his duty with the organization of the ELS congress in Brussels in June 2002.

Great scientist and clinician, he is the wise man, carefully balancing the possible options before making his decisions.

Thanks to this wisdom, he greatly contributed to the development of our journal, making the European Archives of Oto-Rhino-Laryngology one of the best journals of our speciality.

We just hope that we will be able to walk in his steps. 